\title{
Case Report of First-line \\ Chemotherapy of an Advanced Lung Cancer Patient Using Bevacizumab Combined With Pemetrexed Disodium and Carboplatin
}

\author{
Pengbo Deng ${ }^{1}$, Huaping Yang ${ }^{1 *}$, Bingrong Zhao ${ }^{1}$, Yuanyuan $\mathrm{Li}^{1}$, \\ Chengping $\mathrm{Hu}^{1}$ \\ ${ }^{1}$ Department of Respiratory Medicine, Xiangya Hospital, Central South \\ University, Changsha, Hunan 410008, P.R. China.
}

*Corresponding Author: Huaping Yang, Email: liying971@sina.com.

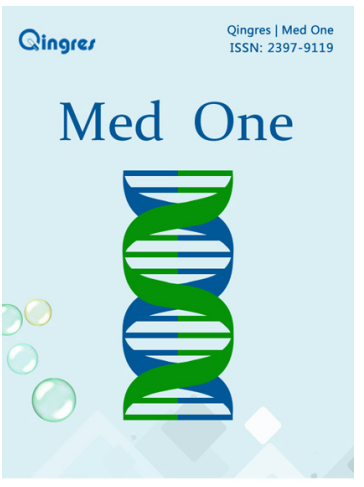

http://mo.qingres.com

\section{GOPEN ACCESS}

DOI: 10.20900/mo.201600012

Received: March 12, 2016

Accepted: May 15, 2016

Published: June 25, 2016

Copyright: $\odot 2016$ Cain et al. This is an open access article distributed under the terms of the Creative Commons Attribution License, which permits unrestricted use, distribution, and reproduction in any medium, provided the original author and source are credited.

\begin{abstract}
A single case of a male stage-IV lung cancer patient is reported, there were exon 19 deletion mutations in the epidermal growth factor receptor (EGFR). Intra-, and extrapulmonary, lesions occurred a month after gefitinib and erlotinib applications. Patient was then switched to the first-line chemotherapy program. Both types of lesions significantly improved four weeks after a combined therapy of pemetrexed disodium + carboplatin + bevacizumab $(7.5 \mathrm{mg} / \mathrm{Kg} \mathrm{d} 1)$, two weeks after continuous therapy with pemetrexed disodium + bevacizumab $(7.5 \mathrm{mg} /$ $\mathrm{Kg} \mathrm{d1).} \mathrm{Short-term} \mathrm{efficacy} \mathrm{was} \mathrm{assessed} \mathrm{as} \mathrm{PR,} \mathrm{without} \mathrm{significant}$ adverse effects, reflecting program efficacy and good tolerance.
\end{abstract}

Key Words: Bevacizumab; Chemotherapy; Non-small Cell Lung Cancer

\section{INTRODUCTION}

A 66-year old male patient with a smoking history was received by the Outpatient Department on September 14, 2015 due to "coughing for 
more than one month". Main symptoms included a dry cough, a small amount of white phlegm, but freedom from fever, chest pains, bloody sputum, and any other discomfort. Stage IV-lung cancer is associated with anorexia and a loss of nearly 10 pounds. The patient had a poor constitution in the past, with a history of "acute hepatitis", "type2 diabetes" and "obsolete pulmonary tuberculosis". The patient was accepted in the Department of Respiratory Medicine on September 15. The results of a lung CT scan indicated a "space occupied for posterior basal segment of right inferior lung and enlarged for mediastinal lymph nodes". The patient was approved for a CT-guided transthoracic needle biopsy, immunohistochemistry, EGFR gene mutation detection, and systemic metastases assessment. He was diagnosed as "primary lung cancer, right lung adenocarcinoma, T4N3M1B (lung, pleura and brain), and stage-IV EGFR Exon 19 deletion mutation (Fig. $1 \mathrm{~A}$ and Fig. 2A)".
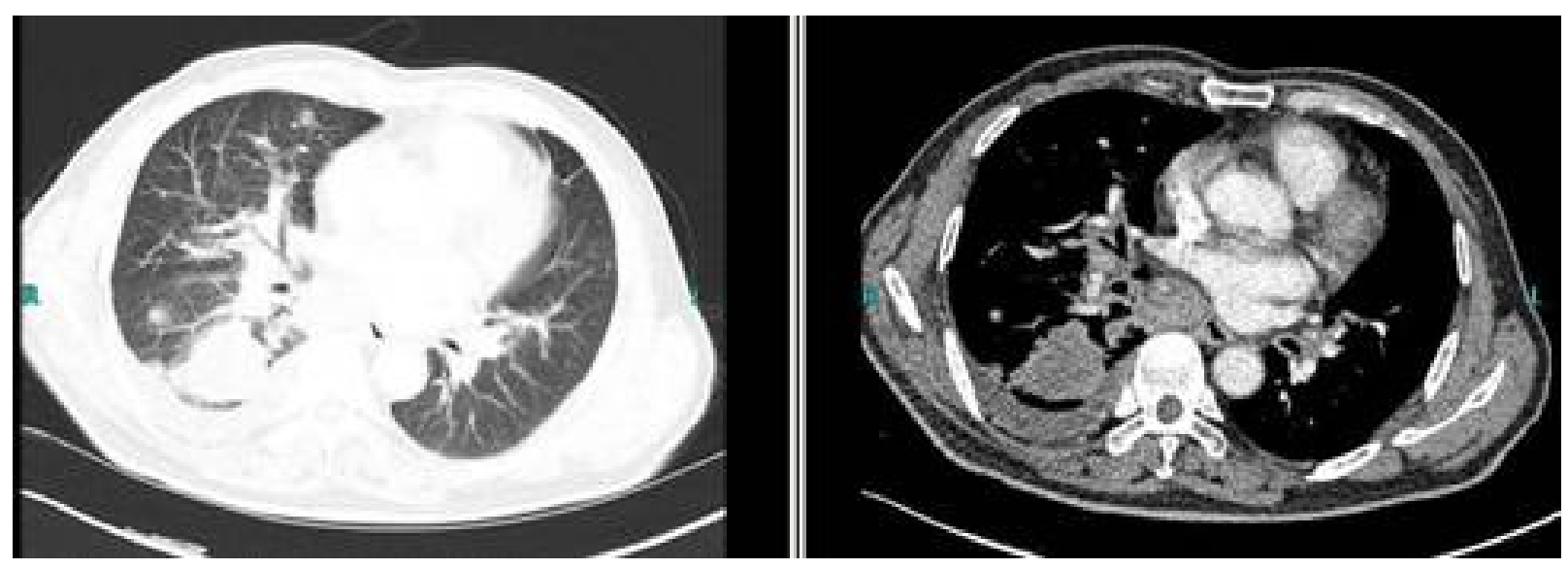

Fig. 1A 2015-9-12: CT image of lung prior to treatment (September 12, 2015);
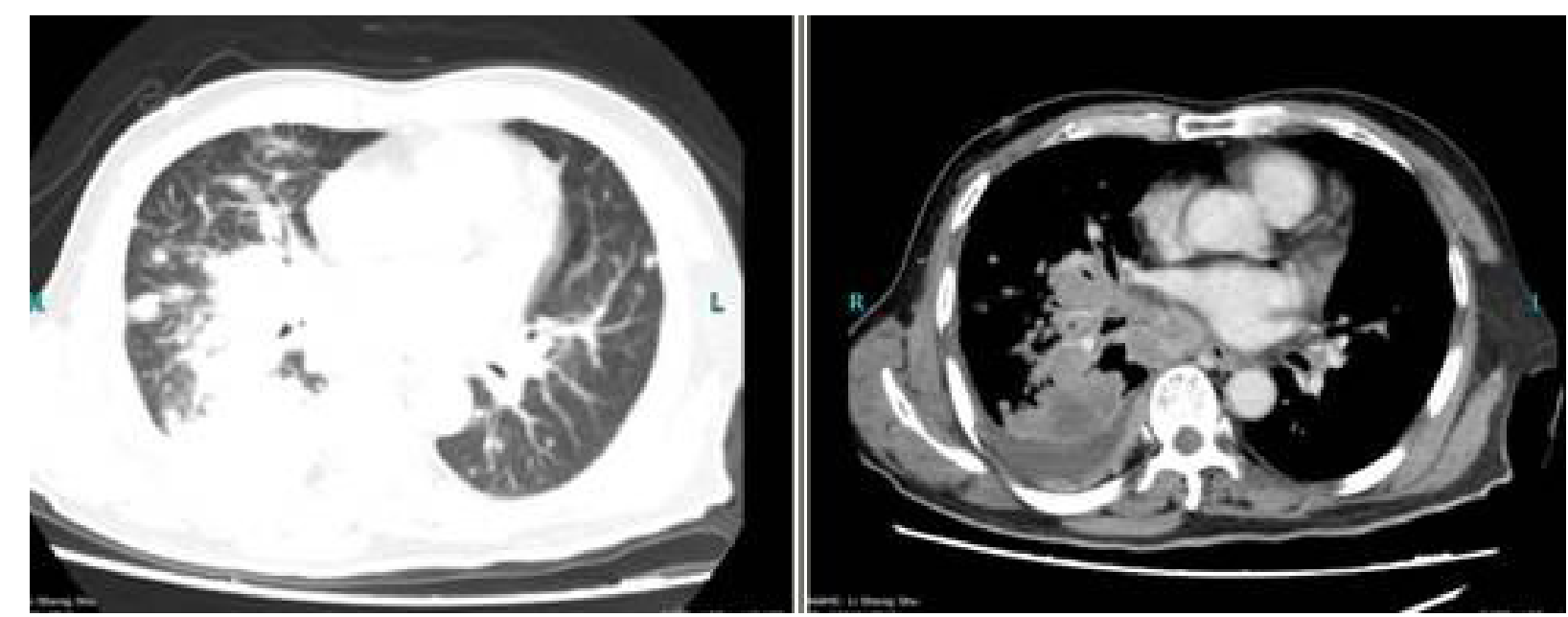

Fig. 1B 2015.10.20 : CT images of lung one month after gefitinib and erlonat administration (October 20, 2015 and November 16, 2015) respectively, indicating a significant progressive disease of lung lesions; 


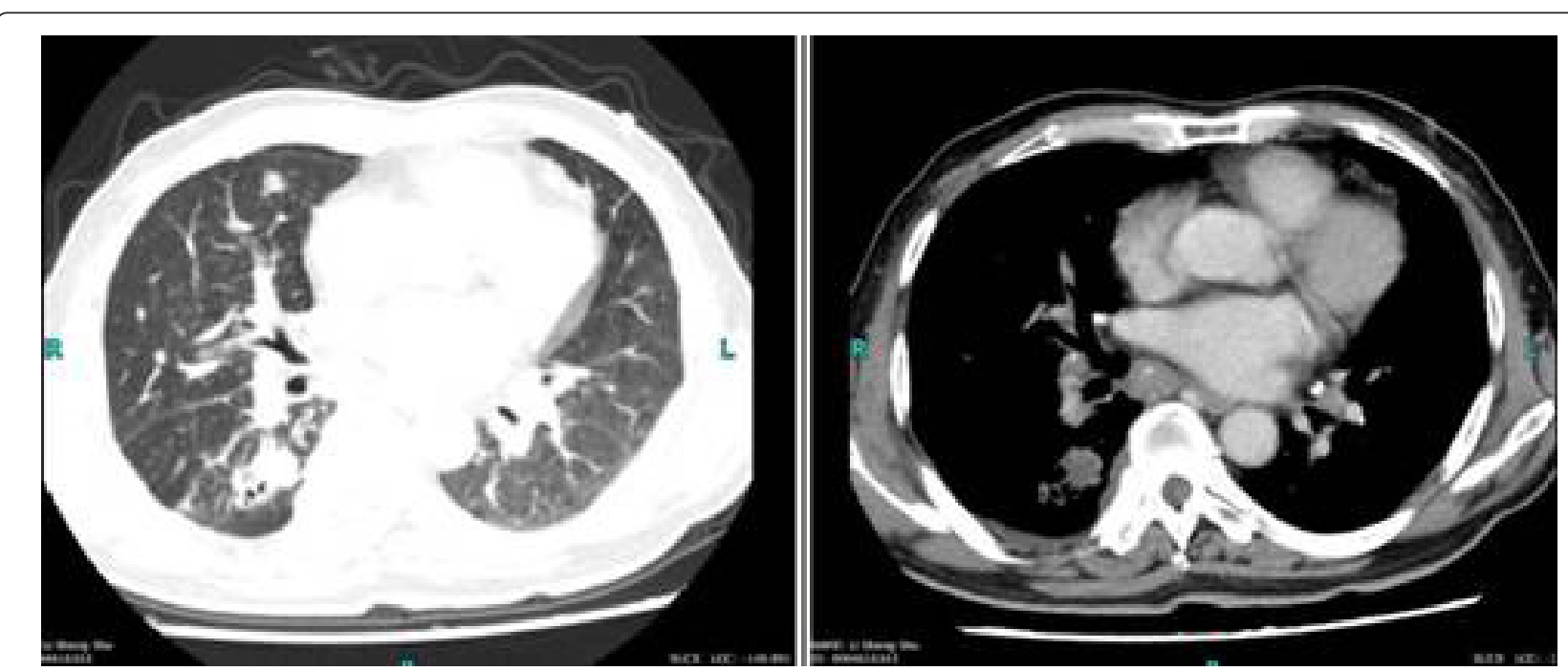

Fig. 1C 2015.11.16: CT images of lung one month after gefitinib and erlonat administration (October 20, 2015 and November 16, 2015) respectively, indicating a significant progressive disease of lung lesions;
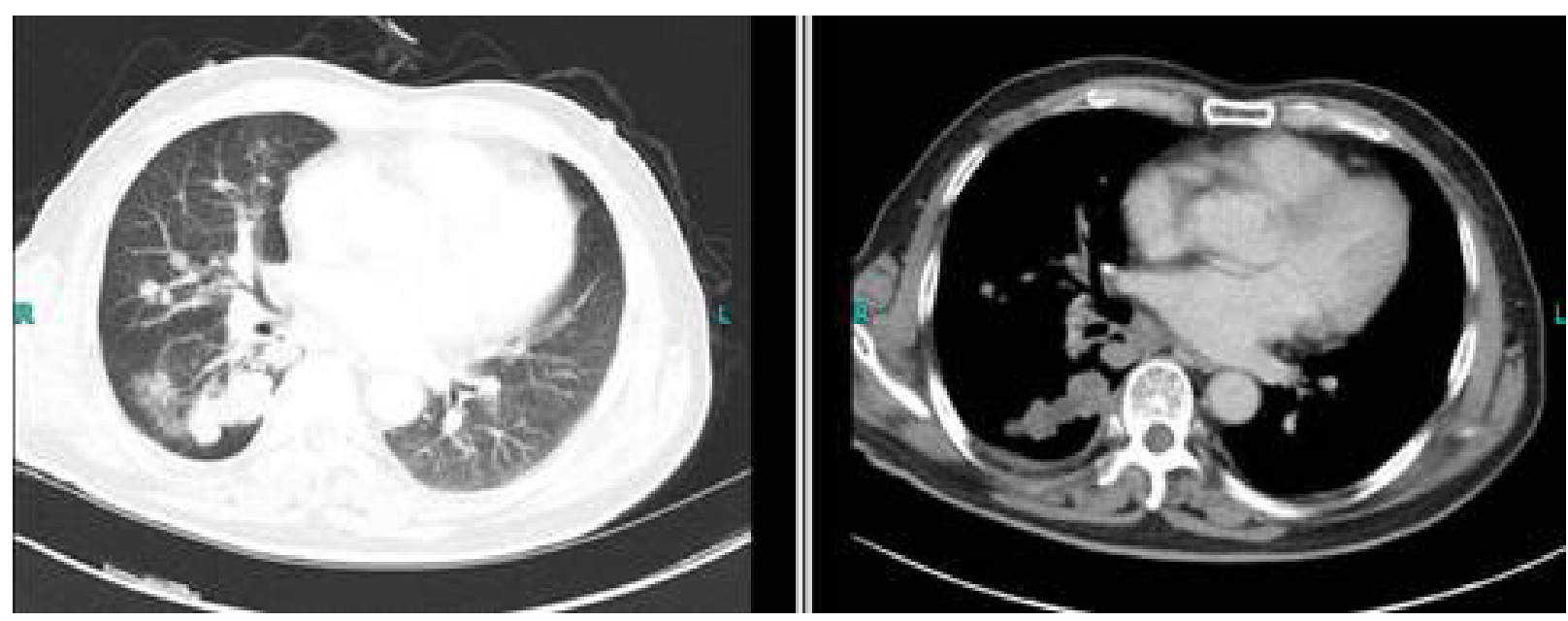

Fig. 1D 2016.1.6 : CT image of lung two and four cycles after a combined program of Pemetrexed disodium (500 mg/m2 d1) + Carboplatin (AUC 5 d1) + Bevacizumab (7.5 mg/Kg d1) (January 6, 2016 and February 11, 2016), indicating a significant lessening of lung lesions.
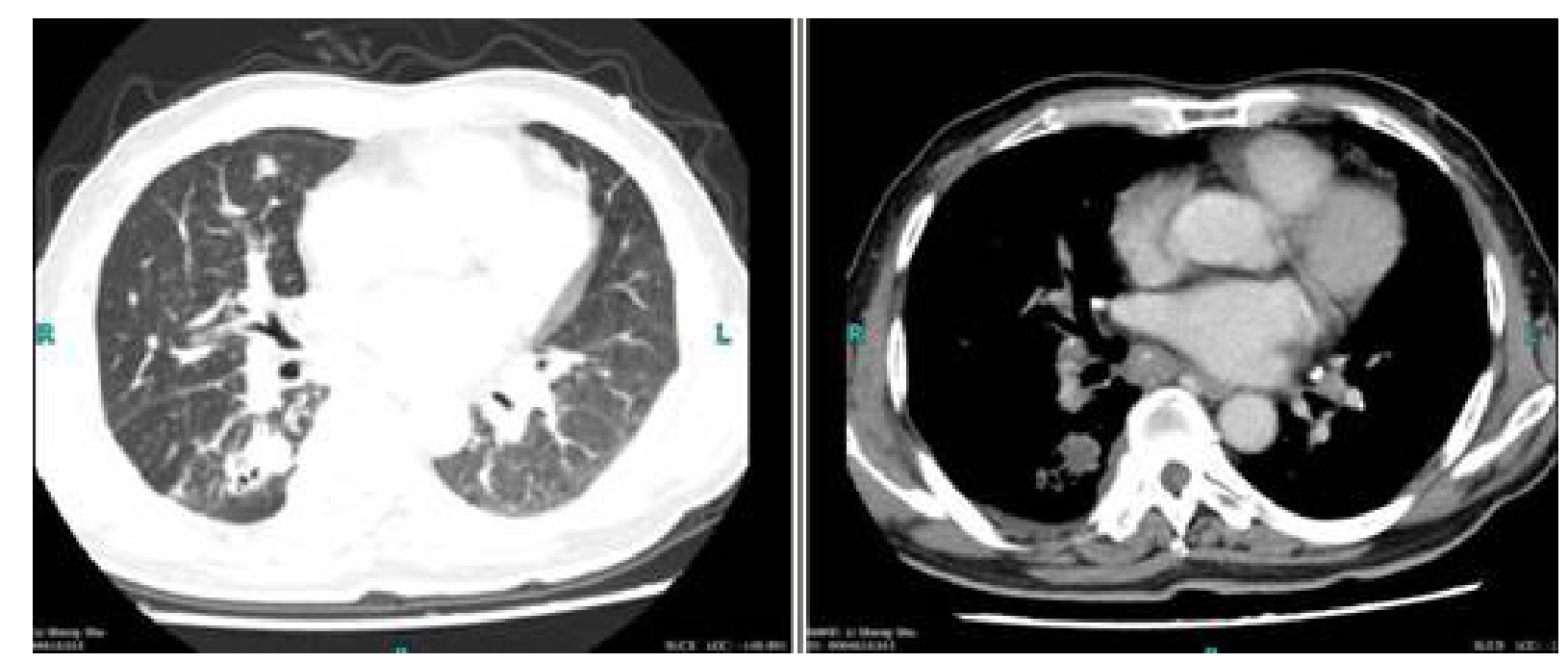

Fig. 1E 2016.2.11 : Efficacy is assessed as PR; 

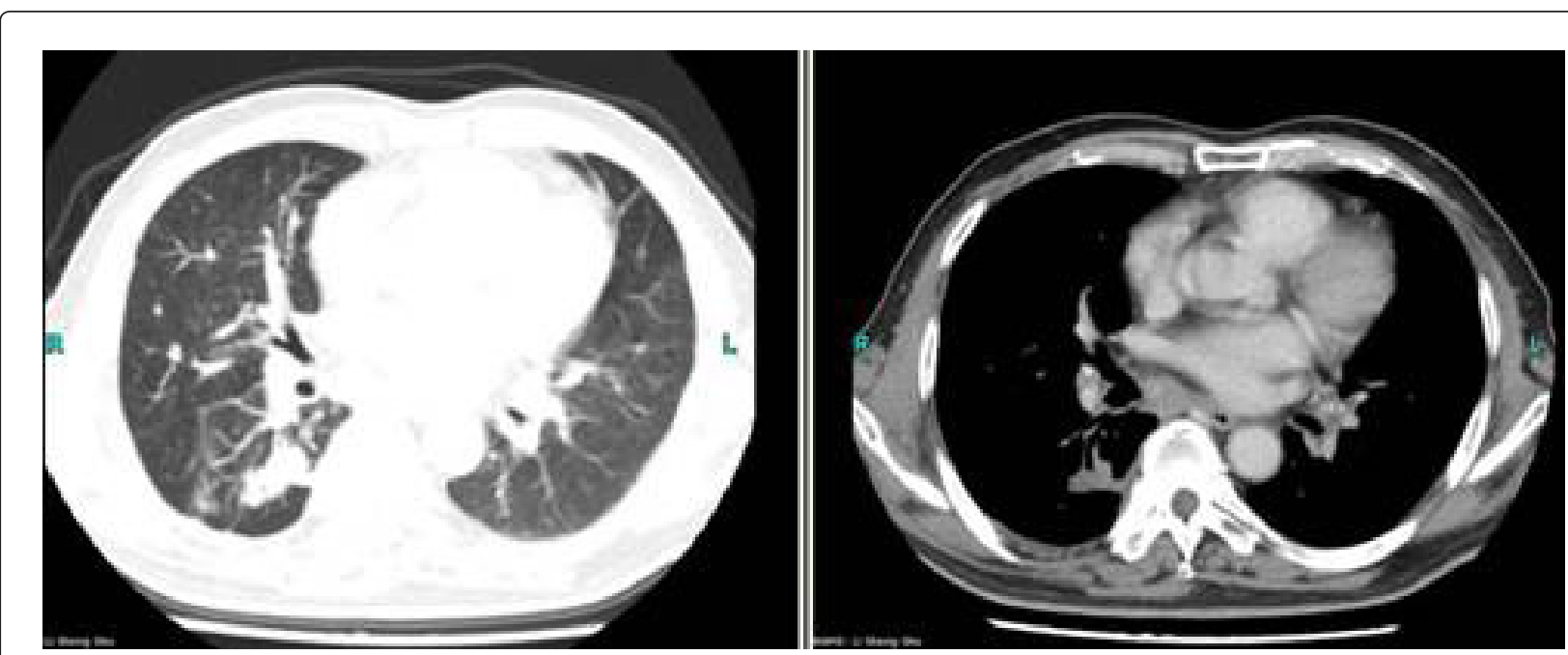

Fig. 1F 2016.4.18 : CT images of lung after maintaining a two-cycle treatment using Pemetrexed disodium (500 mg/m2 d1) + Bevacizumab (7.5 mg/Kg d1) (April 18, 2016), indicating unchanged lung lesions.
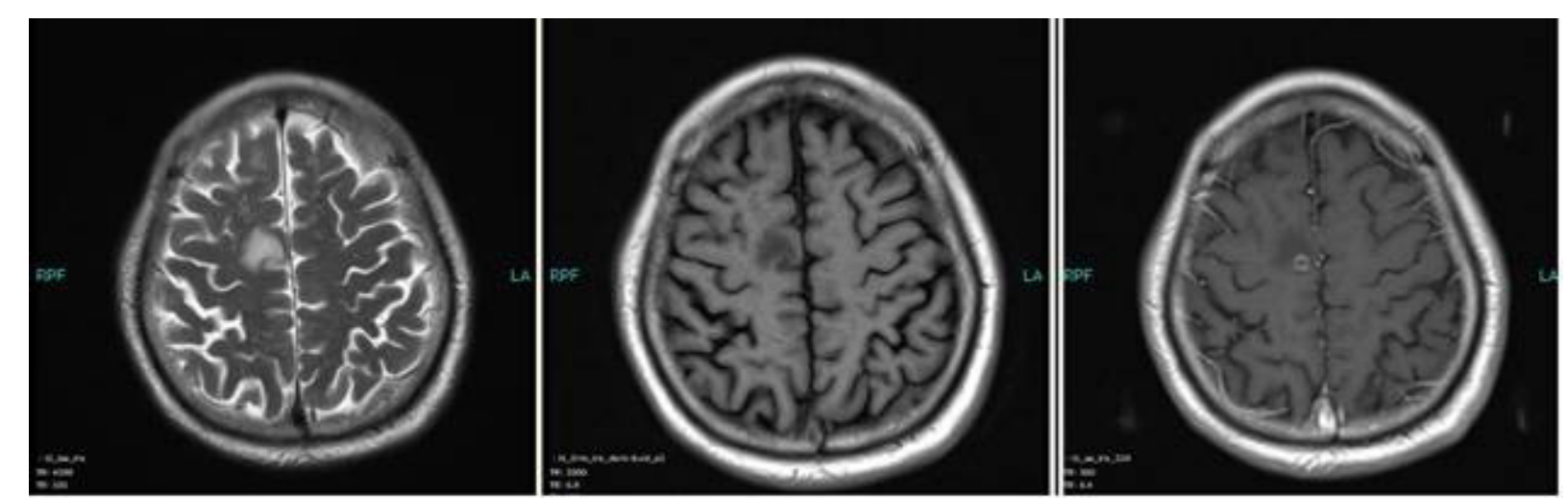

Fig. 2A 2015.9.22 : A pre-treatment cranial MRI image (September 22, 2015);
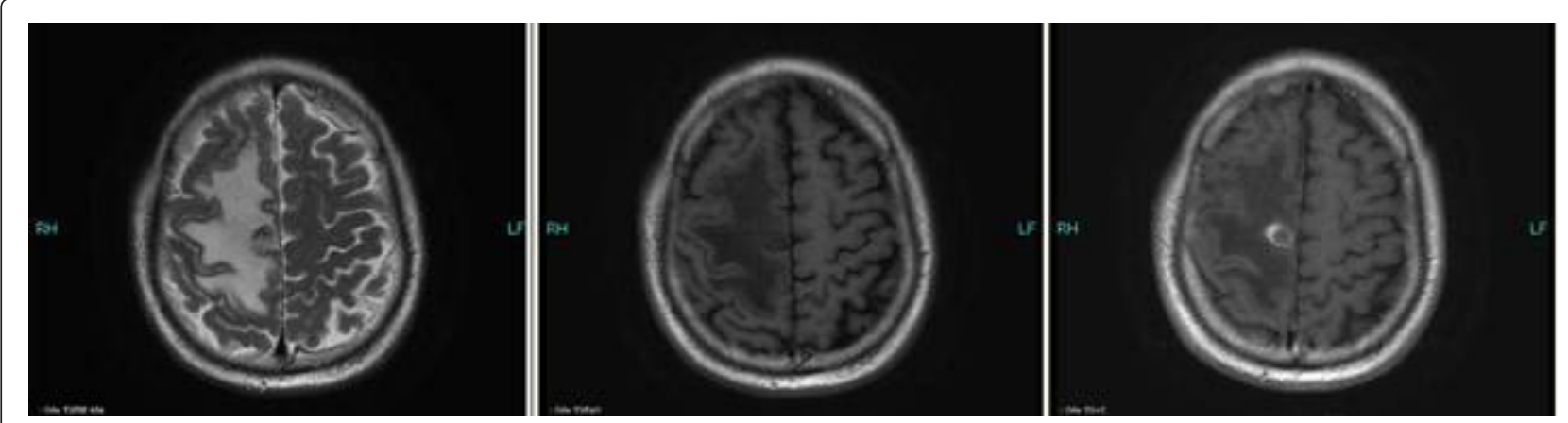

Fig. 2B 2015.11.14 : MRI cranial image one month after gefitinib and erlonat administration (November 14, 2015), showing a significant enlargement of intracranial lesions; 


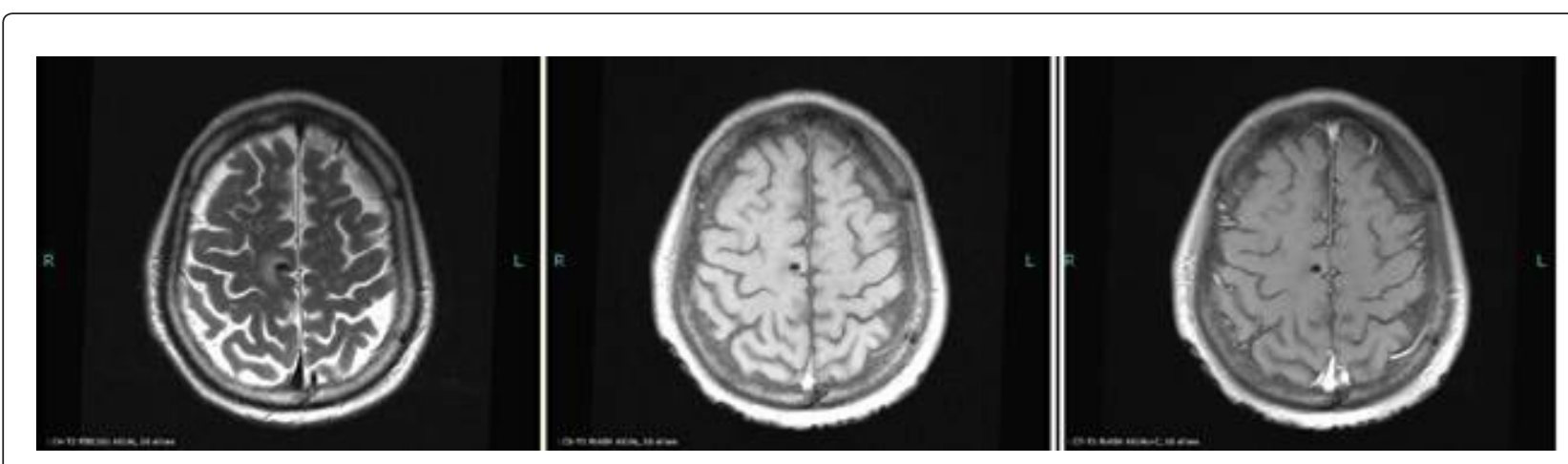

Fig. 2C 2016.1.7 : MRI cranial image of two cycles after combined Pemetrexed disodium (500 mg/m2 d1) + Carboplatin (AUC $5 \mathrm{~d} 1$ ) + Bevacizumab $(7.5 \mathrm{mg} / \mathrm{Kg} \mathrm{d} 1$ ) program (January 7, 2016), indicating a decrease of intracranial lesions and a significant contraction of surrounding edema zone;

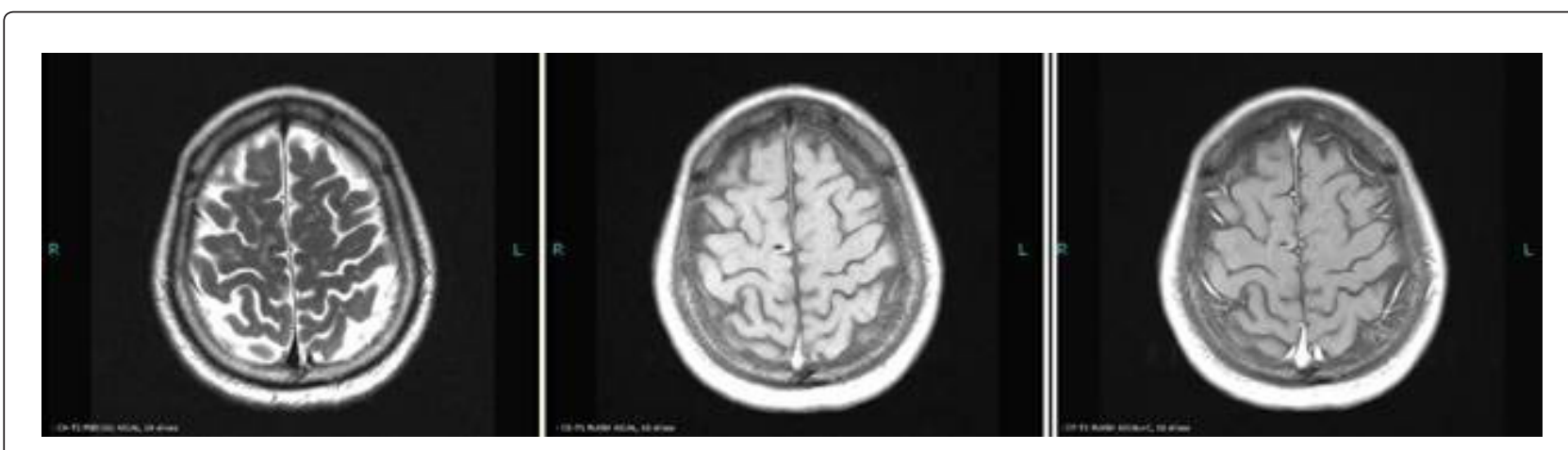

Fig. 2D 2016.4.10 : MRI cranial image after maintaining two-cycle treatment using Pemetrexed disodium (500 $\mathrm{mg} / \mathrm{m} 2 \mathrm{~d} 1)+$ Bevacizumab (7.5 mg/Kg d1) (April 10, 2016), indicating a stable intracranial lesion as before.

The patient checked for further treatment on November 23, 2015. A pre-chemotherapy assessment was made and the results showed multiple bone metastases and multiple enlarged lymph nodes in the left shoulder blade, the fourth lumbar, the right iliac bone and other locations. Performance status (PS) was only one point. Pemetrexed Disodium (500 mg/m2 d1) + Carboplatin (AUC $5 \mathrm{~d} 1)$ + Bevacizumab (7.5 mg/Kg d1) was administered beginning November 26, 2015 for the chemotherapy treatment and supportive therapy was provided, such as, dehydration, reduction of intracranial pressure, promotion of bone repair, pain relief, and waist protection. After discharge, the coughing basically disappeared and the dizziness, backaches, and hemiparesthesia of the left side were significantly improved. Patient emotional state and sleep quality was significantly improved. It was basically normal after a routine blood examination. A second chemotherapy treatment was successfully completed on December 18 (the program is idem). The patient returned to the hospital on January 6 ,
2016 and was proposed for a third chemotherapy. The pre-chemotherapy assessment showed that the measurable, targeted right lung lesion had decreased $(3.2 \mathrm{~mm}$, with a rate of decrease 44.8 \%) (Fig. 1D). Lymphangitis carcinomatosa was significantly decreased and right frontal nodulus lesions were reduced significantly (Fig. 2C). No new lesions were found. Efficacy was assessed as partial relief (PR). A third and fourth chemotherapies were completed on January 9 and January 30, 2016. Efficacy was re-assessed as PR (Fig. 1E) with lung CT review as an outpatient on February 11. Since then, the patient had been subjected to a combined administration program of pemetrexed disodium (500 mg/m2 d1) + bevacizumab $(7.5 \mathrm{mg} / \mathrm{Kg} \mathrm{d} 1)$ for continued chemotherapy. A lung CT and a cranial MRI were peformed on April 16. The results showed that the control of lung lesions and intracranial lesions were basically the same as before (Fig.1F and Fig. 2D). The patient had no cough, backaches, or hemiparesthesia and the quality life significantly improved. PS was decreased to zero. 


\section{DISCUSSION}

Lung biopsy specimens indicated that there was an EGFR exon 19 deletion mutation. According to the Guideline of National Comprehensive Cancer Network (NCCN) in $2015^{[1]}$ reommendations, a therapy program using EGFR tyrosinekinase inhibitors (TKIs) -Gefitinib administration was begun. However, intrapulmonary and extrapulmonary lesions occurred after gefitinib and erlotinib were administered indicating that a primary resistance to EGFR Tki.

Assuming treatment failure, a combined program of platinum-based doublets + bevacizumab was implemented, according to recommendations contained in the NSCLC Guideline of the 2015 NCCN ${ }^{[1]}$, to ensure the improvement of symptoms and patient quality of life over the short term. This included contracting and control of primary lesions of the lung, spinal, and intracranial lesions.

We were aware that a new generation of anticancer drugs for molecular targets might become research and treatment highlights for advanced lung cancer and, wished to ensure that our current treatment program developed in an "individualized" direction. Factors including the genetic locus of EGFR, and chinodem microtubule-associated protein-like 4/ anaplastic lymphoma kinase (EML4ALK) fused genes, need the presence of a specific genetic locus mutation to ensure the patient will benefit from the corresponding targeted-therapy medications. Mutation frequency should be below $10 \%$ and the EGFR can be up to $50 \%$ in the Asian race.

Another molecular-targeted drug, vascular molecular-targeted drug, such as bevacizumab can inhibit the combination of VEGF with its receptors to degenerate tumor angiogenesis and normalize surviving blood vessels and inhibit blood vessel reproduction so as to continue to inhibit tumor growth and metastasis ${ }^{[2,4]}$. The patient's primary resistance against EGFR Tki in this case argued for a bevacizumab-based chemotherapy program, as recommended in the guidelines, as it is more suitable for an individualized patient treatment. It appears he has, indeed, benefited from this treatment program.

A total of 878 patients with relapsed, or stage III-IV non-squamous NSCLC, was included into the stage-III clinical trials (ECOG4599 Trial ${ }^{[5]}$ ) conducted by Sandler. They were randomly classified into two groups and administered paclitaxel + carboplatin, and paclitaxel + carboplatin +bevacizumab, respectively. The results showed that an overall survival (OS), median PFS and ORR of the bevacizumab-containing group superior to the healthy controls $(p<0.05)$. The OS of the patients with advanced NSCLC was prolonged for over a year for the first time in history. Therefore, the FDA approved the combined program of paclitaxel + carboplatin +bevacizumab for treatment of advanced non-squamous NSCLC. Another stage-III clinical trial (AVAIL Trial ${ }^{[6]}$ ) confirmed the results of ECOG4599 Trial ${ }^{[5]}$ from the aspects of its efficacy and PFS. A chemotherapy program combining bevacizumab with platinum-based doublets was approved by the European Medicines Evaluation Agency (EMEA) in 2007 for the first-line treatment of metastatic NSCLC. Many studies (SAiL ${ }^{[7]}$, ARIES) showed that bevacizumab enabled patient OS with advanced NSCLC to be prolonged for over a year. Among the 314 Asian patients in the study of SAiL, TTP was 8.3 months and median OS was 18.9 months. Both of which are all significantly higher than the general population.

The current (2016) NSCLC clinical practice guideline for NCCN clearly states that a first-line chemotherapy program for advanced non-squamous cancer NSCLC includes doublet chemotherapy as well as bevacizumab + chemotherapy, and bevacizumb should be administered during the progressive disease PD period. Chemotherapy programs are composed of several combinations, including, paclitaxel + carboplatin, paclitaxel + cisplatin, vinorelbine + cisplatin, gemcitabine + cisplatin, pemetrexed disodium + cisplatin, and docetaxel + cisplatin. In the United States, common programs include pemetrexed disodium + cisplatin (carboplatin), and paclitaxel + carboplatin combined with, or without, bevacizumb. Forty-nine patients with non-squamous NSCLC were included into a stage-II clinical trial conducted by Patel, et al. ${ }^{[8]}$. All patients accepted the first-line chemotherapy of pemetrexed disodium + carboplatin combined with bevacizumb. In a later period, they continuously accepted a chemotherapy of pemetrexed disodium + bevacizumb. The results showed that the median PFS, OS and ORR reached 7.8 months, 14.1 months and $55 \%$, respectively. No severe adverse events were observed. Similarly, in a similar stageII clinical trial conducted by Japanese Yokoi $\mathrm{T}^{[9]}$, the same treatment program was implemented with 26 patients having stage IIIB-IV NSCLC. The trial results showed that median PFS, and OS, reached 8.6 months and 18.6 months, respectively, indicating that this treatment program may provide more benefits to Asians.

Similar long-term efficacy was obtained in clinical observations of "first-line treatments of bevacizumb combined with pemetrexed disodium + oxaliplatin for advanced NSCLC" carried out by OLIVIER et al. ${ }^{[10]}$. At the same time, a trial made by 
POINTBREAK ${ }^{[11]}$ showed a program of pemetrexed disodium + carboplatin + bevacizumb to be a reasonable option. It was believed that a paclitaxel -based program had more toxicity than a pemetrexed disodium based program. This is mainly reflected in neurotoxicity, but there was no significant differences of OS between the two programs. Therefore, a more appropriate option according to the specific situation of the patients can be made.

In this case, four cycles of combined chemotherapy program of pemetrexed disodium + carboplatin+bevacizumb $(7.5 \mathrm{mg} / \mathrm{Kg} \mathrm{d} 1)$ were performed on the patient and chemotherapy was continued with pemetrexed disodium + bevacizumb $(7.5 \mathrm{mg} / \mathrm{Kg} \mathrm{d} 1)$. In a short-term efficacy assessment, benefits to the patients were observed. However, any long-term efficacy of a chemotherapy program combined with bevacizumb relies mainly on a maintenance administration of this drug and it is necessary to carry out close follow-up observations.

In terms of side effects, no common myelosuppression, liver or kidney dysfunction, gastrointestinal reactions, hypertension, proteinuria, thrombosis, hemorrhages or other reactions ${ }^{[12]}$ were observed during the treatment process of this case. This indicates a good tolerance for this combined program in the treatment of advanced NSCLC. However, it may also be that the related side effects of bevacizumab are dose-dependent ${ }^{[13]}$.

\section{REFERENCES}

1. Wood DE, Kazerooni E, Baum SL, Dransfield MT, Eapen GA, Ettinger DS, Hou L, Jackman DM, Klippenstein D, Kumar R, Lackner RP, Leard LE, Leung AN, Makani SS, Massion PP, Meyers BF, Otterson GA, Peairs K, Pipavath S, Pratt-Pozo C, Reddy C, Reid ME, Rotter AJ, Sachs PB, Schabath MB, Sequist LV, Tong BC, Travis WD, Yang SC, Gregory KM, Hughes M, Nathinal comprehension cancer network. Lung cancer screening, version 1.2015: featured updates to the NCCN guidelines. J Natl Compr Canc Netw. 2015; 13(1): 23-34.

2. Ferrara N. Vascular endothelial growth factor as a target for anticancer therapy. Oncologist. 2004; 9 Suppl 1: 2-10.

3. Willett CG, Boucher Y, Tomaso E, Duda DG, Munn LL, Tong RT, Chung DC, Sahani DV, Kalva SP, Kozin SV, Mino M, Cohen KS, Scadden DT,

\section{CONCLUSION}

In summary, the combined chemotherapy program of pemetrexed disodium + carboplatin + bevacizumb $(7.5 \mathrm{mg} / \mathrm{Kg} \mathrm{d} 1)$ was implemented for four cycles to a patient with advanced lung cancer who with an EGFR exon 19 deletion mutation and primary resistance against the EGFR Tki. It was maintained with pemetrexed disodium + bevacizumb $(7.5 \mathrm{mg} /$ $\mathrm{Kg} \mathrm{d} 1)$ for two cycles. The short-term efficacy was assessed as PR without obvious adverse effects. It reflects the efficacy and good tolerance of this program, which provides more clinical evidence which supports clinical application.

\section{FUNDING}

National Key Scientific \& Technology Support Program: Collaborative innovation of Clinical Research for chronic obstructive pulmonary disease and lung cancer, NO.2013BAI09B09;

Young Scientists Fund in National Natural Science Foundation of China (Program Number: 81502699).

Hartford AC, Fischman AJ, Clark JW, Ryan DP, Zhu AX, Blaszkowsky LS, Chen HX, Shellito $P C$, Lauwers GY, Jain RK. Direct evidence that the VEGF-specific antibody bevacizumab has antivascular effects in human rectal cancer. Nat Med. 2004; 10(2): 145-147.

4. Gerber HP, Ferrara N. Pharmacology and pharmacodynamics of bevacizumab as monotherapy or in combination with cytotoxic therapy in preclinical studies. Cancer Res. 2005; 65(3): 671-680.

5. Sandler A, Gray R, Perry MC, Brahmer J, Schiller JH, Dowlati A, Lilenbaum R, Johnson $\mathrm{DH}$. Paclitaxel-carboplatin alone or with bevacizumab for non-small-cell lung cancer. $\mathrm{N}$ Engl J Med. 2006; 355(24): 2542-2550.

6. Reck M, von PJ, Zatloukal P, Ramlau R, Gorbounova V, Hirsh V, Leighl N, Mezger J, 
Archer V, Moore N, Manegold Cl. Phase III trial of cisplatin plus gemcitabine with either placebo or bevacizumab as first-line therapy for nonsquamous non-small-cell lung cancer: AVAil. J Clin Oncol. 2009; 27(8): 1227-1234.

7. Crinò L, Dansin E, Garrido P, Griesinger F, Laskin J, Pavlakis N, Stroiakovski D, Thatcher N, Tsai CM, Wu YL, Zhou C. Safety and efficacy of first-line bevacizumab-based therapy in advanced non-squamous non-small-cell lung cancer (SAiL, MO19390): a phase 4 study. Lancet Oncol. 2010; 11(8): 733-740.

8. Patel JD, Hensing TA, Rademaker A, Hart EM, Blum MG, Milton DT, Bonomi PD. Phase II study of pemetrexed and carboplatin plus bevacizumab with maintenance pemetrexed and bevacizumab as first-line therapy for nonsquamous non-small-cell lung cancer. J Clin Oncol. 2009; 27(20): 3284-3289.

9. Yokoi T, Torii $Y$, Katashiba $Y$, Sugimoto $H$, Tanijiri T, Ogata M, Inagaki N, Kibata K, Hayashi M, Niki M, Shimizu T, Miyara T, Kurata T, Nomura S. Phase II study of pemetrexed and carboplatin plus bevacizumab, followed by maintenance pemetrexed and bevacizumab in Japanese patients with non-squamous non-small cell lung cancer. Oncol Lett. 2014; 8(6): 2453-2457.

10. Mir O, Boudou-Rouquette P, Giroux J, Chapron J, Alexandre J, Gibault L, Ropert S, Coriat R,
Durand JP, Burgel PR, Dusser D, Goldwasser F. Pemetrexed, oxaliplatin and bevacizumab as first-line treatment in patients with stage IV non-small cell lung cancer. Lung Cancer. 2012; 77(1): 104-109.

11. Patel JD, Socinski MA, Garon EB, Reynolds $\mathrm{CH}$, Spigel DR, Olsen MR, Hermann RC, Jotte RM, Beck T, Richards DA, Guba SC, Liu J, Frimodt-Moller B, John WJ, Obasaju CK, Pennella EJ, Bonomi Philip, Govindan R. PointBreak: a randomized phase III study of pemetrexed plus carboplatin and bevacizumab followed by maintenance pemetrexed and bevacizumab versus paclitaxel plus carboplatin and bevacizumab followed by maintenance bevacizumab in patients with stage IIIB or IV nonsquamous non-small-cell lung cancer. J Clin Oncol. 2013; 31(34): 4349-4357.

12. Avastin (bevacizumab) pakage insert. South San Francisco, CA: Genentech Inc. 2009. Available from: http://www.fda.gov/downloads/ Drugs/DevelopmentApprovalProcess/ HowDrugsareDevelopedandApproved/ A p p r o v a I A p p I i c a t i o n s / erapeuticBiologicApplications/ucm080453.pdf.

13. Zhu X, Wu S, Dahut WL, Parikh CR. Risks of proteinuria and hypertension with bevacizumab, an antibody against vascular endothelial growth factor: systematic review and meta-analysis. Am J Kidney Dis. 2007; 49(2): 186-193. 